\title{
Validation of a Dynamic Energy Budget (DEB) model for the blue mussel Mytilus edulis
}

\author{
S. Saraiva ${ }^{1,2,3, *}$, J. van der Meer ${ }^{1,2}$, S. A. L. M. Kooijman ${ }^{2}$, R. Witbaard ${ }^{1}$, \\ C. J. M. Philippart ${ }^{1}$, D. Hippler ${ }^{4}$, R. Parker $^{5}$

\begin{abstract}
${ }^{1}$ Royal Netherlands Institute for Sea Research (NIOZ), PO Box 59, 1790 AB Den Burg, Texel, The Netherlands ${ }^{2}$ Vrije Universiteit, Department of Theoretical Biology, de Boelelaan 1087, 1081 HV Amsterdam, The Netherlands ${ }^{3}$ Instituto Superior Técnico, Environment and Energy Section, Av. Rovisco Pais, 1, 1049-001 Lisboa, Portugal

${ }^{4}$ Technical University Berlin, Department of Mineralogy, Sekr. ACK 9, Ackerstrasse 76, 13355 Berlin, Germany
\end{abstract} \\ ${ }^{5}$ Centre for Environment, Fisheries \& Aquaculture Science (CEFAS), Pakefield Road, Lowestoft, Suffolk NR33 0HT, UK
}

\begin{abstract}
A model for bivalve growth was developed and the results were tested against field observations. The model is based on the Dynamic Energy Budget (DEB) theory and includes an extension of the standard DEB model to cope with changing food quantity and quality. At 4 different locations in the North Sea (Wadden Sea, Sean Gas Field, Oyster Grounds and Dogger Bank), labelled blue mussels Mytilus edulis were kept under natural conditions. Shell length was repeatedly measured for each mussel during the experiment, and dry weight was determined at the end of the experiment for some of the mussels. Temperature, salinity, chlorophyll concentration and Secchi depth (at the Wadden Sea location) were measured next to the experimental sites. Model performance was evaluated by comparing predicted and measured shell length, dry weight and growth at each location for each individual, without changing parameter values that were previously obtained from independent studies. The results show that the model was able to reproduce the main patterns of the observations, implying that the main metabolic processes at the individual level are well described.
\end{abstract}

KEY WORDS: Modelling $\cdot$ Dynamic Energy Budget theory $\cdot$ Bivalve growth $\cdot$ Model validation · Mytilus edulis

\section{INTRODUCTION}

Bivalves have been extensively studied, and a wide range of modelling approaches has been used to describe their ecology. Each of the existing models has been developed from a particular perspective and with a particular set of objectives, ranging from a simple filtration model, with feeding and excretion being the main processes, to more complex models, where filtration, particle rejection and selection, food absorption efficiency and reproduction are described as functions of environmental conditions. Most of these models describe nutrition and resource allocation as allometric relationships. The so-called net-production models assume that assimilated energy is immediately available for maintenance and that the remaining energy is available for growth, or stored as reserve (e.g. Bacher et al. 1991, Grant \& Bacher 1998, Scholten \& Smaal 1998, Ren \& Ross 2001). The Dynamic Energy Budget (DEB) theory, proposed by Kooijman (1986) and extensively discussed by Kooijman $(2000,2010)$, is based on a more mechanistic view and has already been successfully applied to model bivalve dynamics (e.g. Ross \& Nisbet 1990, van Haren \& Kooijman 1993, Bacher \& Gangnery 2006, Pouvreau et al. 2006, Troost et al. 2010). The DEB the- 
ory is conceptually different from the net-production models approach, because it assumes that all assimilated energy is first stored as reserve (which does not require maintenance); subsequently, the reserve is utilized to fuel other metabolic processes such as maintenance, growth, development and reproduction. In addition, DEB models do not use empirical allometric relationships but simply state that food uptake is proportional to the surface area of the body, whereas maintenance scales mainly to structural body volume. One of the main advantages of a DEB model is that it is based on a generic theory, meaning that the same model structure can be applied to different species, where only parameter values differ. Variability in growth and reproduction between individuals of the same species are assumed to be mainly caused by differences in environmental conditions (temperature, food). Interspecific variability (among several species) is caused both by differences in parameter values as well as environmental conditions (Kooijman 2000, 2010). Here we aimed to test to what extent a generic model for an individual mussel is realistic enough to be used for population modelling in the future. The obtained model results were compared with real observations on the growth of the blue mussel Mytilus edulis at 4 different locations in the North Sea, with 1 station in a coastal environment and 3 stations in the open sea (off shore).

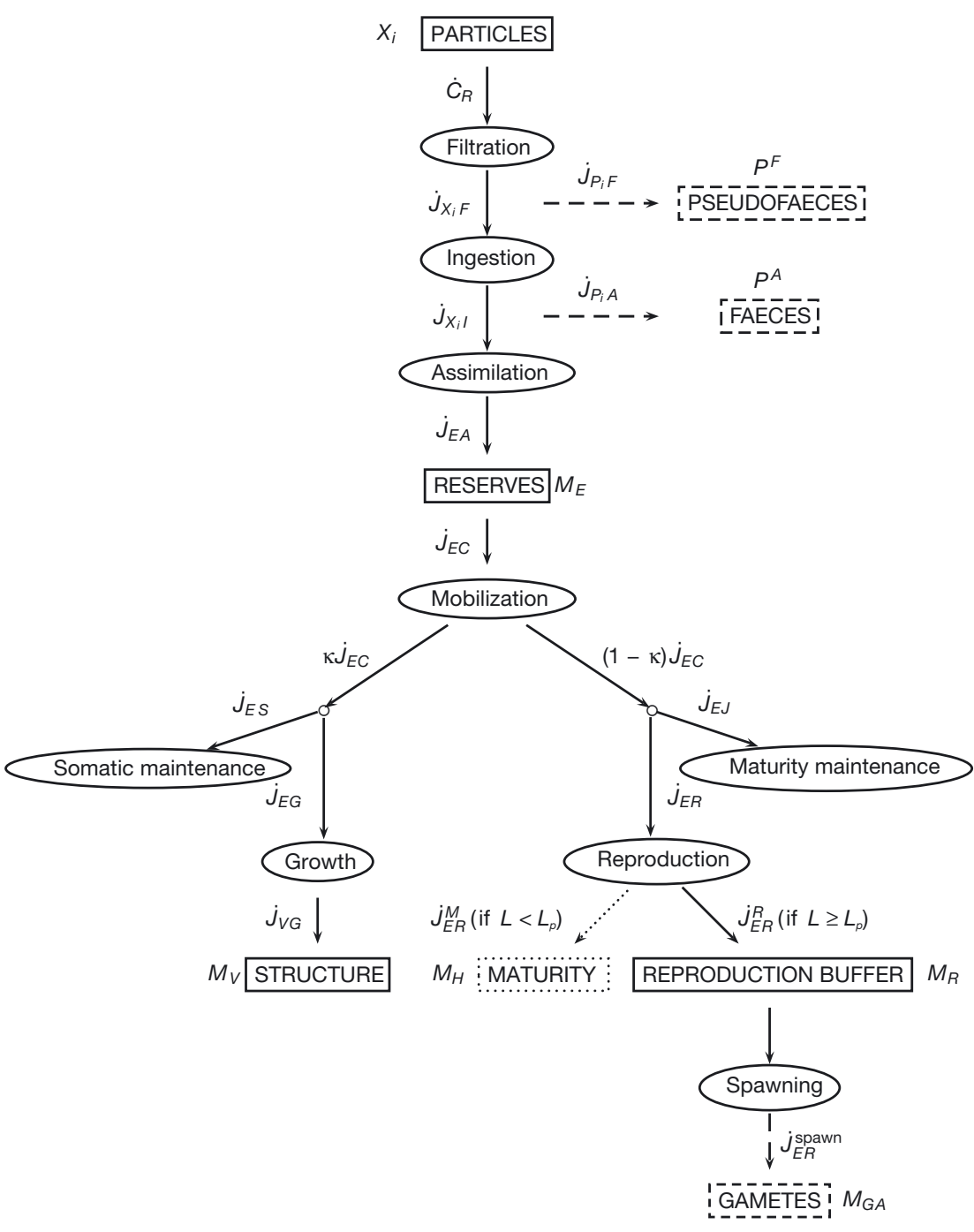

Fig. 1. Global scheme for the Dynamic Energy Budget (DEB) model for bivalves. Ellipses represent the main processes involved in organism metabolism, and mass fluxes are indicated as $\dot{J}_{*}$. See Tables 1 to 4 for variable descriptions. Boxes with solid lines represent the organism mass compartments and solid arrows the associated flux; the dotted box represents energy investment and the dotted arrow its inflow; dashed boxes represent a mass compartment outside the organism, and dashed arrows represent the respective outflow from the organism

\section{MATERIALS AND METHODS}

\section{DEB model}

The standard DEB model, described by Kooijman (2010), was adapted and extended using the feeding processes model proposed by Saraiva et al. (2011b). The basic assumptions of the DEB model are:

(1) an organism is characterized by a structural body (individual structure biomass), reserve (biomass available for direct use), maturity level (amount of energy spent in organism development) and a reproduction buffer (biomass allocated to future gamete production);

(2) the chemical composition (with $\mathrm{C}, \mathrm{H}, \mathrm{O}, \mathrm{N}$ and $\mathrm{P}$ assumed to be the main elements) of reserve and structure are constant (strong homeostasis);

(3) if food density is constant, then the ratio between reserve and structure (reserve density) tends to maintain a constant value even during growth (weak homeostasis);

(4) the life cycle of the individual has 3 different life stages: embryonic (no feeding, the embryo relies on 
stored energy supplies), juvenile (feeding starts but resources are not yet allocated to the reproduction buffer) and adult (organism is mature and able to reproduce);

(5) metabolic switching (from embryo to juvenile and juvenile to adult) is linked to maturity level;

(6) K-rule: a fixed fraction of mobilized reserve is used for somatic maintenance and growth (increase of structural mass), the rest for maturity maintenance and maturation (increase of maturity in embryos and juveniles) or reproduction (adults); and

(7) somatic maintenance is proportional to the amount of structure, and maturity maintenance is proportional to the level of maturity.

In addition, for the specific case, the presented model also assumes that:

(1) the bivalve is an isomorph organism (i.e. its shape does not change during growth);

(2) the conversion between the real and the structural length is made by a fixed dimensionless shape coefficient $\left(\partial_{M}\right)$;

(3) time is partioned into food searching and food handling, where food searching depends on food density and food handling and digestion depend on food quality; and

(4) rejuvenation (i.e. decrease in maturity) and shrinking (i.e. decrease in structure) can occur during extreme starvation.

Fig. 1 represents a scheme of the model, and Tables 1 to 4 show the main formulations and necessary parameters used in the model. A more detailed description of the model and its specific assumptions is provided in the following sections.

\section{State variables and forcing functions}

Four state variables characterize the organism, i.e. the individual structure biomass, $M_{V}\left(\mathrm{~mol} \mathrm{C}^{V}\right)$; reserve, $\left.M_{E}(\mathrm{~mol} \mathrm{C})^{E}\right)$; maturity level, $M_{H}\left(\mathrm{~mol} \mathrm{C}^{E}\right)$ and reproduction buffer, $M_{R}\left(\mathrm{~mol} \mathrm{C}{ }^{E}\right)$ (Table 1$)$. The forcing functions of the model are ambient temperature and the concentration of particles in the water, either inorganic (non-food material, expressed in $\mathrm{mg}^{-1}$ ) or algae (food, expressed in $\mathrm{mol}^{-1}$ for $\mathrm{C}, \mathrm{N}$, and P).

\section{Feeding}

Filtration, ingestion and assimilation are assumed to be separate processes (Saraiva et al. 2011b). The Synthesizing Units (SU) concept, introduced in the DEB theory by Kooijman $(1998,2000,2010)$, is used to specify those processes. For each particle type $i$ in the water column, with density $X_{i}$ a flux of particles is retained through filtration (the product of clearance rate and particle concentration, $X_{i} \dot{C}_{R}$ ). In the model, clearance rate is regulated by substitutable and sequential SUs, where any substrate can be separately filtered and the handling of 1 food type by the filtration apparatus interferes with the possible handling of other food types. Once retained in the gills, particles are then led to the palps, where selection is made between particles transported to the mouth to be ingested and particles which are rejected and transported back to the water as pseudofaeces $\left(\dot{J}_{P_{i} F}\right)$. The same type of mechanism (substitutable and sequential SUs) is used to explain and describe both

Table 1. Model state variables and forcing functions. See Tables 2, 3 \& 4 for further variable descriptions

\begin{tabular}{|c|c|c|c|}
\hline Symbol & Description & Units & Formulation \\
\hline$M_{V}$ & Bivalve structure biomass & $\mathrm{mol} \mathrm{C}$ & $\frac{\mathrm{d} M_{V}}{\mathrm{~d} t}=\dot{J}_{V G}$ \\
\hline$M_{E}$ & Bivalve reserve biomass & $\operatorname{mol~C} C^{E}$ & $\frac{\mathrm{d} M_{E}}{\mathrm{~d} t}=\dot{J}_{E}=\dot{J}_{E A}-\dot{J}_{E C}$ \\
\hline$M_{H}$ & Bivalve maturity investment & $\mathrm{mol} \mathrm{C}^{E}$ & $\frac{\mathrm{d} M_{H}}{\mathrm{~d} t}=\dot{J}_{E R}^{M}$ \\
\hline$M_{R}$ & Bivalve reproduction buffer & $\mathrm{mol} \mathrm{C}^{E}$ & $\frac{\mathrm{d} M_{R}}{\mathrm{~d} t}=\dot{J}_{E R}^{R}$ \\
\hline$T$ & Temperature & $\mathrm{K}$ & \\
\hline$X_{0}$ & Inorganic particle concentration & $\mathrm{mg} \mathrm{l}^{-1}$ & \\
\hline$X_{1}$ & Algal concentration & $\mathrm{mol} \mathrm{Cl}^{-1}$ & \\
\hline$n_{X_{1}}^{N}$ & Algal nitrogen:carbon ratio & $\mathrm{mol} \mathrm{N} \mathrm{mol}{ }^{-1} \mathrm{C}$ & \\
\hline$n_{X_{1}}^{P}$ & Algal phosphorus:carbon ratio & $\mathrm{mol} \mathrm{P} \mathrm{mol}{ }^{-1} \mathrm{C}$ & \\
\hline
\end{tabular}


Table 2. Model formulations: feeding process description adapted from Saraiva et al. (2011b) and standard DEB model adapted from Kooijman (2010). See Tables 1, 3 \& 4 for further variable descriptions

\begin{tabular}{|c|c|c|c|c|}
\hline Process & Symbol & Description & Units & Formulation \\
\hline \multirow[t]{2}{*}{ Filtration } & $\dot{C}_{R}$ & Clearance rate & $\mathrm{m}^{3} \mathrm{~d}^{-1}$ & $\dot{C}_{R}=\frac{\left\{\dot{C}_{R m}\right\}}{1+\sum_{i=0}^{1} \frac{X_{i}\left\{\dot{C}_{R m}\right\}}{\left\{\dot{J}_{X_{i} F m}\right\}}} V^{2 / 3}$ \\
\hline & $\dot{J}_{X_{i} F}$ & Filtration rate & $\mathrm{mol} \mathrm{C} \mathrm{d}{ }^{-1} \mathrm{~g} \mathrm{~d}^{-1}$ & $\dot{J}_{X_{i} F}=\dot{C}_{R} X_{i}$ \\
\hline \multirow[t]{2}{*}{ Ingestion } & $\dot{J}_{X_{i} I}$ & Ingestion rate & $\mathrm{mol} \mathrm{C} \mathrm{d}^{-1} \mathrm{~g} \mathrm{~d}^{-1}$ & $\dot{J}_{X_{i} I}=\frac{\rho_{X_{i} I} \dot{J}_{X_{i} F}}{1+\sum_{i}^{n} \frac{\rho_{X_{i} I} \dot{J}_{X_{i} F}}{\left\{\dot{J}_{X_{i} I m}\right\}}}$ \\
\hline & $\dot{J}_{P_{i} F}$ & Pseudofaeces production rate & $\mathrm{mol} \mathrm{C} \mathrm{d} \mathrm{g} \mathrm{d}^{-1}$ & $\dot{J}_{P_{i} F}=\dot{J}_{X_{i} F}-\dot{J}_{X_{i} I}$ \\
\hline \multirow[t]{8}{*}{ Assimilation } & $\dot{J}_{E A}$ & Assimilation rate & $\operatorname{mol~C} \mathrm{C}^{-1}$ & $\dot{J}_{E A}=\dot{J}_{E A^{E}}+\dot{J}_{E A^{V}}$ \\
\hline & $\dot{J}_{E A^{V}}$ & Algal structure assimilation rate & $\operatorname{mol~C} \mathrm{d}^{-1}$ & $\dot{J}_{E A^{V}}=y_{E X^{V}} \dot{J}_{X_{1} I}\left(1-f_{E}\right)$ \\
\hline & $\dot{r}_{C}$ & - & $\operatorname{mol~C} \mathrm{C}^{-1}$ & $\dot{r}_{C}=\dot{J}_{X_{1} I} f_{E}$ \\
\hline & $\dot{r}_{N}$ & - & $\operatorname{mol~C} \mathrm{C}^{E} \mathrm{~d}^{-1}$ & $\dot{r}_{N}=\dot{J}_{X_{1} I} f_{E} \frac{n_{X_{1}}^{N}}{n_{E}^{N}}$ \\
\hline & $\dot{r}_{P}$ & - & $\operatorname{mol~C} \mathrm{d}^{-1}$ & $\dot{r}_{P}=\dot{J}_{X_{1} I} f_{E} \frac{n_{X_{1}}^{P}}{n_{E}^{P}}$ \\
\hline & $\dot{J}_{E A^{E}}$ & Algal reserve assimilation rate & $\operatorname{mol~C}^{E} \mathrm{~d}^{-1}$ & 1 \\
\hline & & $J_{E A^{E}}=$ & $=\left(\frac{\overline{\dot{r}_{C}}}{\dot{r}_{N}}+\frac{-}{\dot{r}_{P}}\right.$ & $\left.\overline{\dot{r}_{C}+\dot{r}_{N}}-\overline{\dot{r}_{C}+\dot{r}_{P}}-\overline{\dot{r}_{N}+\dot{r}_{P}}+\overline{\dot{r}_{C}+\dot{r}_{N}+\dot{r}_{P}}\right)$ \\
\hline & $\dot{J}_{P_{i} I}$ & Faeces production rate & $\mathrm{mol} \mathrm{C} \mathrm{d}^{-1}$ & $\dot{J}_{P_{i} I}=\dot{J}_{X_{i} I}-\dot{J}_{E A}$ \\
\hline Mobilization & $\dot{J}_{E C}$ & Mobilization flux & $\operatorname{mol~C} \mathrm{C}^{-1}$ & $\dot{J}_{E C}=\frac{\left[E_{m}\right]}{\underline{\left[E_{G}\right]}+\kappa[E]}\left(\frac{\left[E_{G}\right]}{\mu_{E}} \dot{V} V^{2 / 3}+\dot{J}_{E S}\right)$ \\
\hline & & & & $\overline{\mu_{E}}$ \\
\hline $\begin{array}{l}\text { Somatic } \\
\text { maintenance }\end{array}$ & $\dot{J}_{E S}$ & Somatic maintenance & $\operatorname{mol~C} \mathrm{C}^{-1}$ & $\dot{J}_{E S}=\frac{\left[\dot{p}_{M}\right]}{\mu_{E}} V$ \\
\hline \multirow[t]{3}{*}{ Growth } & $\dot{J}_{E G}$ & Flux allocated to growth & $\operatorname{mol~C} \mathrm{d}^{-1}$ & $\dot{J}_{E G}=\kappa \dot{J}_{E C}-\dot{J}_{E S}$ \\
\hline & $\dot{J}_{V G}$ & Growth & $\operatorname{mol~C} \mathrm{C}^{-1}$ & $\dot{J}_{V G}=y_{V E} \dot{J}_{E G}$ \\
\hline & $\dot{J}_{E J}$ & Maturity maintenance & $\operatorname{mol~C} \mathrm{d}^{-1}$ & $\dot{J}_{E J}=\dot{k}_{J} M_{H}$ \\
\hline \multirow{3}{*}{$\begin{array}{l}\text { Maturity and } \\
\text { reproduction }\end{array}$} & $\dot{J}_{E R}$ & Flux allocated to reproduction/maturity & $\operatorname{mol~C}{ }^{E} d^{-1}$ & $\dot{J}_{E R}=(1-\kappa) \dot{J}_{E C}-\dot{J}_{E J}$ \\
\hline & $\dot{J}_{E R}^{M}$ & Flux to maturity & $\operatorname{mol~C} \mathrm{C}^{-1}$ & $\dot{J}_{E R}^{M}=\left\{\begin{array}{l}\dot{J}_{E R}, \text { if } M_{H}<M_{H}^{p} \\
0, \text { otherwise }\end{array}\right.$ \\
\hline & $\dot{J}_{E R}^{R}$ & Flux to reproduction buffer & $\operatorname{mol~C} \mathrm{C}^{-1}$ & $\dot{J}_{E R}^{R}=\left\{\begin{array}{c}0, \text { if } M_{H}<M_{H}^{p} \\
\dot{J}_{E R}, \text { otherwise }\end{array}\right.$ \\
\hline \multirow[t]{2}{*}{ Spawning } & $\dot{J}_{E R}^{\text {spawn }}$ & Spawning & $\operatorname{mol~C} \mathrm{C}^{-1}$ & $\dot{J}_{E R}^{\text {spawn }}=\left\{\begin{array}{l}k_{R} M_{R} / R^{\text {spawn }}, \text { if } \\
\text { GSR } \geq \text { GSR }^{\text {spawn }} \wedge T \geq T^{\text {spawn }} \\
0, \text { otherwise }\end{array}\right.$ \\
\hline & $N^{\text {spawn }}$ & Number of gametes released & No. $d^{-1}$ & $N^{\text {spawn }}=\dot{J}_{E R}^{\text {spawn }} / M_{E}^{0}$ \\
\hline
\end{tabular}


Table 2 (continued)

\begin{tabular}{|c|c|c|c|c|}
\hline Process & Symbol & Description & Units & Formulation \\
\hline \multirow{6}{*}{$\begin{array}{l}\text { Inorganic } \\
\text { fluxes }\end{array}$} & $\dot{J}_{\mathrm{NH}_{3}}$ & Ammonia flux & $\mathrm{mol} \mathrm{N} \mathrm{d}{ }^{-1}$ & $\dot{J}_{\mathrm{NH}_{3}}=-\left(-\dot{J}_{X_{i} F} n_{X_{1}}^{N}+\dot{J}_{P_{i} F} n_{X_{1}}^{N}+\dot{J}_{P_{i} I} n_{X_{1}}^{N}+\dot{J}_{V G} n_{V}^{N}+\dot{J}_{E} n_{E}^{N}+\dot{J}_{E R}^{R} n_{E}^{N}\right)$ \\
\hline & $\dot{J}_{\mathrm{PO}_{4}}$ & Phosphate flux & $\mathrm{mol} \mathrm{P} \mathrm{d} \mathrm{d}^{-1}$ & $\dot{J}_{\mathrm{PO}_{4}}=-\left(-\dot{J}_{X_{i} F} n_{X_{1}}^{P}+\dot{J}_{P_{i} F} n_{X_{1}}^{P}+\dot{J}_{P_{i} I} n_{X_{1}}^{P}+\dot{J}_{V G} n_{V}^{P}+\dot{J}_{E} n_{E}^{P}+\dot{J}_{E R}^{R} n_{E}^{P}\right)$ \\
\hline & $\dot{J}_{\mathrm{H}_{2} \mathrm{O}}$ & Water flux & $\mathrm{mol} \mathrm{H} \mathrm{d}{ }^{-1}$ & $\dot{J}_{\mathrm{H}_{2} \mathrm{O}}=-\left(-\dot{J}_{X_{i} F} n_{X_{1}}^{H}+\dot{J}_{P_{i} F} n_{X_{1}}^{H}+\dot{J}_{P_{i} I} n_{X_{1}}^{H}+3 \dot{J}_{\mathrm{NH}_{3}}+\dot{J}_{V G} n_{V}^{H}+\dot{J}_{E} n_{E}^{H}+\dot{J}_{E R}^{R} n_{E}^{H}\right)$ \\
\hline & $\dot{J}_{\mathrm{CO}_{2}}$ & $\begin{array}{l}\text { Carbon dioxide } \\
\text { flux }\end{array}$ & $\mathrm{mol} \mathrm{C} \mathrm{d}^{-1}$ & $\dot{J}_{\mathrm{CO}_{2}}=-\left(-\dot{J}_{X_{i} F}+\dot{J}_{P_{1} F}+\dot{J}_{P_{1} I}+\dot{J}_{\mathrm{NH}_{3}}+\dot{J}_{V G}+\dot{J}_{E}+\dot{J}_{E R}^{R}\right)$ \\
\hline & $\dot{J}_{\mathrm{O}_{2}}$ & Dioxygen flux & $\mathrm{mol} \mathrm{O}_{2} \mathrm{~d}^{-1}$ & \\
\hline & & & $\dot{J}_{\mathrm{O}_{2}}=-\frac{1}{2}\left(-\dot{J}_{X_{i}}\right.$ & $\left.{ }_{F} n_{X_{1}}^{\circ}+4 \dot{J}_{\mathrm{PO}_{4}}+2 \dot{J}_{\mathrm{H}_{2} \mathrm{O}}+2 \dot{J}_{\mathrm{CO}_{2}}+\dot{J}_{P_{1} F} n_{X_{1}}^{\mathrm{O}}+\dot{J}_{P_{i} I} n_{X_{1}}^{\mathrm{O}}+\dot{J}_{V G} n_{V}^{\circ}+\dot{J}_{E} n_{E}^{\circ}+\dot{J}_{E R}^{R} n_{E}^{\circ}\right)$ \\
\hline
\end{tabular}

filtration and ingestion. The formulation derived is then similar to a Holling type II functional response, although extended to the situation with several types of food. Filtration and ingestion are assumed as $2 \mathrm{SU}$ systems connected by an open handshaking proto$\mathrm{col}$, i.e. the first $\mathrm{SU}$ releases its products irrespective of the state of the next SU, with the consequent production of pseudofaeces (filtered material that the ingestion process is not able to handle). The selection of particles in the ingestion process is made by assuming a different binding probability for each type of food $\left(\rho_{X_{i} I}\right)$, representing a different affinity of the ingestion apparatus (palps) for each particle. The third and last feeding step is assimilation, defined as the process whereby particles are absorbed and converted into the organism's reserve. The efficiency of the conversion of food into the reserve depends on how the organism is able to absorb food particles,

Table 3. Model auxiliary compound parameters and other quantities. See Tables 1, 2 \& 4 for further variable descriptions

\begin{tabular}{|c|c|c|c|}
\hline Symbol & Description & Units & Formulation \\
\hline$V^{1 / 3}$ & Volumetric length & $\mathrm{cm}$ & $V^{1 / 3}=\left(\frac{M_{V}}{\left[M_{V}\right]}\right)^{1 / 3}$ \\
\hline$\left[M_{V}\right]$ & Volume-specific structural mass & $\mathrm{mol} \mathrm{C} \mathrm{Cm}^{-3}$ & {$\left[M_{V}\right]=\frac{d_{V}}{w_{V}}$} \\
\hline$[E]$ & Reserve density & $\mathrm{mol} \mathrm{C} \mathrm{Cm}^{-3}$ & {$\left[E_{m}\right]=\frac{M_{E}}{V}$} \\
\hline$M_{H}^{b}$ & Cumulative maturity at birth & $\operatorname{mol~C}{ }^{E}$ & $M_{H}^{b}=\frac{E_{H b}}{\mu_{E}}$ \\
\hline$M_{H}^{p}$ & Cumulative maturity at puberty & $\operatorname{mol~C}{ }^{E}$ & $M_{H}^{p}=\frac{E_{H p}}{\mu_{E}}$ \\
\hline$Y_{V E}$ & Yield coefficient of structures on reserves & $\mathrm{mol} \mathrm{C}^{V} \mathrm{~mol}^{-1} \mathrm{C}^{E}$ & $Y_{V E}=\frac{\left[M_{V}\right] \mu_{E}}{\left[E_{G}\right]}$ \\
\hline$\dot{k}_{M}$ & Somatic maintenance rate coefficient & $d^{-1}$ & $\dot{k}_{M}=\frac{\left[p_{M}\right]}{\left[E_{G}\right]}$ \\
\hline$\dot{k}_{J}$ & $\begin{array}{l}\text { Volume-specific maturity maintenance } \\
\text { rate coefficient }\end{array}$ & $d^{-1}$ & $\dot{k}_{J}=\dot{k}_{M}$ \\
\hline GSR & Gonado-somatic ratio & $\mathrm{mol} \mathrm{C}{ }^{R} \mathrm{~mol}^{-1} \mathrm{C}$ & $\mathrm{GSR}=\frac{M_{R}}{M_{V}+M_{E}+M_{R}}$ \\
\hline$L$ & Organism length & $\mathrm{cm}$ & $L=\frac{V^{1 / 3}}{\delta_{M}}$ \\
\hline$D W$ & Organism total dry weight & $g(d w)$ & $D W=M_{V} w_{V}+\left(M_{E}+M_{R}\right) w_{E}$ \\
\hline
\end{tabular}


Table 4. Dynamic Energy Budget (DEB) parameters for Mytilus edulis and other parameters and conversion factors. dw: dry weight, max.: maximim, s.a.: surface area

\begin{tabular}{|c|c|c|c|c|}
\hline Symbol & Description & Units & Value & Source \\
\hline$\left\{\dot{C}_{R m}\right\}$ & Maximum surface area specific clearance rate & $\mathrm{m}^{3} \mathrm{~d}^{-1} \mathrm{~cm}^{-2}$ & 0.096 & Saraiva et al. (2011b) \\
\hline$\left\{\dot{J}_{X_{1} F m}\right\}$ & Algal maximum surface area specific filtration rate & $\mathrm{mol} \mathrm{C} \mathrm{d}{ }^{-1} \mathrm{~cm}^{-2}$ & $4.8 \times 10^{-4}$ & Rosland et al. (2009) \\
\hline$\left\{\dot{J}_{X_{0} F m}\right\}$ & Inorganic material max. s.a. specific filtration rate & $\mathrm{g} \mathrm{d}^{-1} \mathrm{~cm}^{-2}$ & 3.5 & Saraiva et al. (2011a) \\
\hline$\rho_{X_{1} I}$ & Algal binding probability & - & 0.4 & Saraiva et al. (2011a) \\
\hline$\rho_{X_{0} I}$ & Inorganic material binding probability & - & 0.4 & Saraiva et al. (2011a) \\
\hline$\dot{J}_{X_{1} I m}$ & Algal maximum ingestion rate & $\mathrm{mol} \mathrm{C} \mathrm{d} \mathrm{d}^{-1}$ & $1.3 \times 10^{4}$ & Saraiva et al. (2011a) \\
\hline$\dot{J}_{X_{0} \operatorname{Im}}$ & Inorganic material maximum ingestion rate & $\mathrm{g} \mathrm{d}^{-1}$ & 0.11 & Saraiva et al. (2011a) \\
\hline$y_{E X^{V}}$ & Yield coefficient of reserves in algal structure & $\mathrm{mol} \mathrm{C} \mathrm{mol}^{-1} \mathrm{C}^{V}$ & 0.75 & Present study \\
\hline$\dot{V}$ & Energy conductance & $\mathrm{cm} \mathrm{d}^{-1}$ & 0.056 & Saraiva et al. (2011a) \\
\hline$\kappa$ & Allocation fraction to growth and somatic maintenar & ance & 0.67 & Saraiva et al. (2011a) \\
\hline$\left[\dot{p}_{M}\right]$ & Volume specific somatic maintenance & $\mathrm{J} \mathrm{d}^{-1} \mathrm{Cm}^{-3}$ & 11.6 & Saraiva et al. (2011a) \\
\hline$\left[E_{G}\right]$ & Specific cost for structure & $\mathrm{J} \mathrm{cm}^{-3}$ & 5993 & Saraiva et al. (2011a) \\
\hline$\delta_{M}$ & Shape coefficient & - & 0.297 & Saraiva et al. (2011a) \\
\hline$M_{E}^{0}$ & Initial reserve mass at optimal food conditions & $\mathrm{mol} \mathrm{C}{ }^{E}$ & $1.48 \times 10^{-10}$ & Saraiva et al. (2011a) \\
\hline$E_{H b}$ & Maturity at birth & $\mathrm{J}$ & $2.99 \times 10^{-5}$ & Saraiva et al. (2011a) \\
\hline$E_{H p}$ & Maturity at puberty & $\mathrm{J}$ & $1.58 \times 10^{2}$ & Saraiva et al. (2011a) \\
\hline$\kappa_{R}$ & Reproduction efficiency & - & 0.95 & Kooijman (2010) \\
\hline$R^{\text {spawn }}$ & Spawning period & $\mathrm{d}$ & 1 & Present study \\
\hline $\mathrm{GSR}^{\min }$ & Minimum gonado-somatic ratio in the organism & $\mathrm{mol} \mathrm{C} \mathrm{mol}^{-1} \mathrm{C}$ & 0.1 & Cardoso et al. (2007) \\
\hline GSR $^{\text {spawn }}$ & Gonado-somatic ratio to spawn & $\mathrm{mol} \mathrm{C} \mathrm{mol}^{-1} \mathrm{C}$ & 0.2 & Present study \\
\hline $\mathrm{T}^{\text {spawn }}$ & Minimum temperature for spawning & ${ }^{\circ} \mathrm{C}$ & 9.6 & Hummel et al. (1989) \\
\hline$T_{\text {ref }}$ & Reference temperature & $\mathrm{K}$ & 293 & Present study \\
\hline$T_{A}$ & Arrhenius temperature & $\mathrm{K}$ & 7022 & van der Veer et al. (2006) \\
\hline$d_{V}=d_{E}$ & Bivalve structure and reserve specific density & $\mathrm{g}_{(\mathrm{dw})} \mathrm{Cm}^{-3}$ & 0.2 & $\begin{array}{l}\text { Rosland et al. (2009), } \\
\text { Brey (2001) }\end{array}$ \\
\hline$\psi_{a f d w / d w}$ & Bivalve ash-free dw to dw conversion factor & - & 0.85 & Present study \\
\hline$\mu_{E}$ & Bivalve reserve chemical potential & $\mathrm{J} \mathrm{mol}^{-1}$ & $6.97 \times 10^{5}$ & van der Veer et al. (2006) \\
\hline$\psi_{\mathrm{dw} / C}$ & Algal dry weight to carbon conversion factor & $g_{(d w)} g^{-1} C$ & 2.5 & $\begin{array}{l}\text { Slobodkin \& Richman } \\
\text { (1961) }\end{array}$ \\
\hline$f_{E}$ & Reserve fraction in algal biomass & - & 0.5 & Present study \\
\hline$\dot{n_{X_{1}}}$ & Chemical composition of food $\left({ }^{*}=\mathrm{C}, \mathrm{H}, \mathrm{O}, \mathrm{N}, \mathrm{P}\right)$ & $\mathrm{mol}^{*} \mathrm{~mol}^{-1} \mathrm{C}$ & $\mathrm{C}_{1} \mathrm{H}_{1.8} \mathrm{O}_{0.53}$ & Kooijman (2010) \\
\hline \multirow[t]{2}{*}{$n_{E}^{*}=n_{V}^{*}$} & $\begin{array}{l}\text { Chemical composition of bivalve reserve/structure } \\
\left({ }^{*}=\mathrm{C}, \mathrm{H}, \mathrm{O}, \mathrm{N}, \mathrm{P}\right)\end{array}$ & $\mathrm{mol}^{*} \mathrm{~mol}^{-1} \mathrm{C}$ & $\mathrm{C}_{1} \mathrm{H}_{1.8} \mathrm{O}_{0.53}$ & Kooijman (2010) \\
\hline & & & $\mathrm{N}_{0.18} \mathrm{P}_{0.006}$ & Smaal \& Vonck (1997) \\
\hline$w_{E}=w_{V}$ & Bivalve reserves/structure relative molecular mass & $g_{(\mathrm{dw})} \mathrm{mol}^{-1}$ & 25.22 & Present study \\
\hline
\end{tabular}


which ultimately depends on the similarity of the chemical composition of food and reserve. Conversion efficiency, therefore, depends on the type of food. The adopted assimilation formulation for algal reserve assumes a parallel and complementary substrate for the synthesis of bivalve reserve tissue. Differences in the chemical composition between bivalve reserve tissue and ingested food determine the production of faeces $\left(\dot{J}_{P_{A} A}\right)$. More details on the model assumptions, formulations and parameter estimations can be found in Saraiva et al. (2011b).

\section{Mobilization}

The mobilization rate, $\dot{J}_{E C}$, is the rate at which energy is used from the reserve. As a consequence of the weak homeostasis assumption, the mobilization of the reserve occurs at a rate proportional to the reserve density, which is the ratio between reserve (mass, mol C) and structure (volume, $\mathrm{m}^{3}$ ), and thus inversely proportional to structure (Kooijman 2010).

\section{Somatic maintenance}

Somatic maintenance, $J_{E S}$, stands for all processes necessary to 'stay alive', or to maintain the integrity of the animal's body, and this maintenance term can generally be decomposed in contributions that are proportional to structural body volume (structure maintenance costs) and to surface area (e.g. osmotic work in brackish waters and endotherms) (Kooijman 2010). This second type of contribution to maintenance (proportional to the organism's surface area) is considered to be null because we assume that the bivalve is not affected by the possible changes in salinity at the study locations and also because bivalves are ectotherms, and thus do not spend energy on temperature regulation.

\section{Growth}

Growth, $\dot{J}_{V G}$, represents the increase in structural body mass of the organism. The flux of reserve available for growth, $\dot{J}_{E G}$, is computed as the difference between the amount of energy allocated to growth/maintenance, following the $\kappa$-rule, and the somatic maintenance. The increase in structural body mass, i.e. growth, is computed by assuming a yield coefficient $\left(y_{V E}\right)$ resulting from the stoichiometric balance of mass transformations (Kooijman 2010).

\section{Maturity and reproduction}

During the juvenile stage, the fraction of energy allocated to reproduction is used to develop reproductive organs and regulation systems, increasing the maturation level of the organism. Maturity itself has no mass, or energy, and it is quantified as the cumulative investment of reserve in maturity. When the organism reaches a particular maturity level $\left(M_{H}^{P}\right)$, no more development is needed and it becomes an adult. Hereafter, it allocates this flux, $\dot{J}_{E R}$, to the reproduction buffer for further gamete production and release into the water. Thus, this maturity threshold controls stage transitions. Maturity requires maintenance, proportional to the maturity level, which can be thought to relate to the maintenance of regulating mechanisms, defense systems and concentration gradients (Kooijman 2010). The present model assumes, for simplicity, that the maturity maintenance rate coefficient is equal to the somatic maintenance rate coefficient, $\dot{k}_{M}=\dot{k}_{J}$ implying that the stage transitions occur at a fixed amount of structure.

\section{Spawning}

The allocation of energy to reproduction is accumulated in a reproduction buffer. This leads to an increase in the gonado-somatic mass ratio (GSR, gonadal tissue fraction of the total biomass) over time. Spawning events occur if the GSR and the temperature are above the respective thresholds (GSR $^{\text {spawn }}$ and $T^{\text {spawn }}$ ). The model considers that gamete production, i.e. the conversion of the reproduction buffer content into embryo reserve, has overhead costs. The dimensionless factor $k_{R}$ represents the fraction that is fixed in eggs, and $1-k_{R}$ is the dissipation fraction. In line with field observations made by Cardoso et al. (2007), the model assumes that 1 spawning event does not empty the reproduction buffer content completely but that a minimum value of GSR is maintained inside the organism. For simplicity, the model considers that each gamete (sperm cell or egg) produced will have a constant value of reserve density that equals the reserve density of the mother when in optimal condition and that the spawning events are instantaneous.

\section{Inorganic compounds}

Mineral fluxes are represented by the amount of $\mathrm{CO}_{2}, \mathrm{H}_{2} \mathrm{O}, \mathrm{O}_{2}, \mathrm{NH}_{3}$ and $\mathrm{PO}_{4}$ used or released by the 
individual in the processes described above. They can be computed on the basis of the principle of mass conservation for each element in the system $(\mathrm{C}, \mathrm{H}, \mathrm{O}$, $\mathrm{N}, \mathrm{P}$ ) using the organic fluxes computed before.

\section{Temperature effect}

All physiological rates depend on the body temperature. This dependency is usually well-described by the Arrhenius relation, within a speciesspecific tolerance range of temperatures:

$$
\dot{k}(T)=\dot{k}_{1} \exp \left(\frac{T_{A}}{T_{1}}-\frac{T_{A}}{T}\right)
$$

where $T$ is the absolute temperature $(\mathrm{K}), T_{1}$ is the reference temperature, $T_{A}$ is the Arrhenius temperature, $\dot{k}_{1}$ is the value of the rate at temperature $T_{1}$, and $\dot{k}(T)$ is the value of the rate at temperature $T$. It is assumed that all physiological rates are affected by temperature in the same way.

\section{Model parameters}

The model parameters used in this study were estimated by Saraiva et al. (2011a) using several data sets from the literature on the blue mussel Mytilus edulis, following the covariation method described by Lika et al. (2011). This method is based on the minimization of the weight sum of squares deviation between data and model results. The data include a collection of observations (single data points and/or time series) and a set of pseudo-data (average of parameters obtained from a large collection of organisms, used to restrict the possible parameter combinations). The general idea behind the covariation method is to let all available information compete, or interact, to produce the end result, implying the estimation of all parameters from all data sets simultaneously. Saraiva et al. (2011a) also provided a comparison with previous parameter sets in terms of model performance and approximation to the data, concluding that the new parameter set should lead to better results. The parameters used in the present study are listed in Table 4 .

\section{Field observations}

Mussels. Intertidal mussels from the Dutch coast (Egmond) and the UK coast (Lowestoft and Wash), with a size range from 2 to $6 \mathrm{~cm}$, were collected and individually marked. Marks consisted of miniature labels (www.hallprint.com) which were glued on 1 of the valves with a gel type of superglue. At the start of the experiment, each individual shell length was measured to the nearest $1 / 10 \mathrm{~mm}$ with digital callipers, and a subset $(\mathrm{n}=195)$ of animals was sacrificed and dissected to determine initial soft tissue weight and condition. The labelled mussels were then transplanted to 4 locations in the North Sea: Wadden Sea, Sean Gas Field (UK), Oyster Grounds (NL) and Dogger Bank (UK) (Fig. 2). Fig. 3 presents the size distribution of the transplanted mussels at each location. The mussels were transplanted in series of small nets $(10 \times 20 \mathrm{~cm}$, with a mesh size of $1.5 \mathrm{~cm}$ ) which were filled with 15 mussels each (Table 5). The resulting 'density of mussels' is in the range of that found in natural mussel banks.

At an inshore part of the North Sea, the Wadden Sea, mussels were located in the surface water layer in December 2005. At this location, the mussels were collected, cleaned and measured individually every month, and a subset of the mussels was sacrificed in the first year for weight determination. During the experimental period (December 2005 until August 2009), 4 new transplantations were done at this location (November 2006, April 2007, June 2008 and November 2008). The transplantations followed the same methodology as the first deployment. For this location, growth data from 148 mussels were available.

At the other locations (North Sea offshore), the same procedure was applied and the nets were tied to bottom moorings which were deployed from October

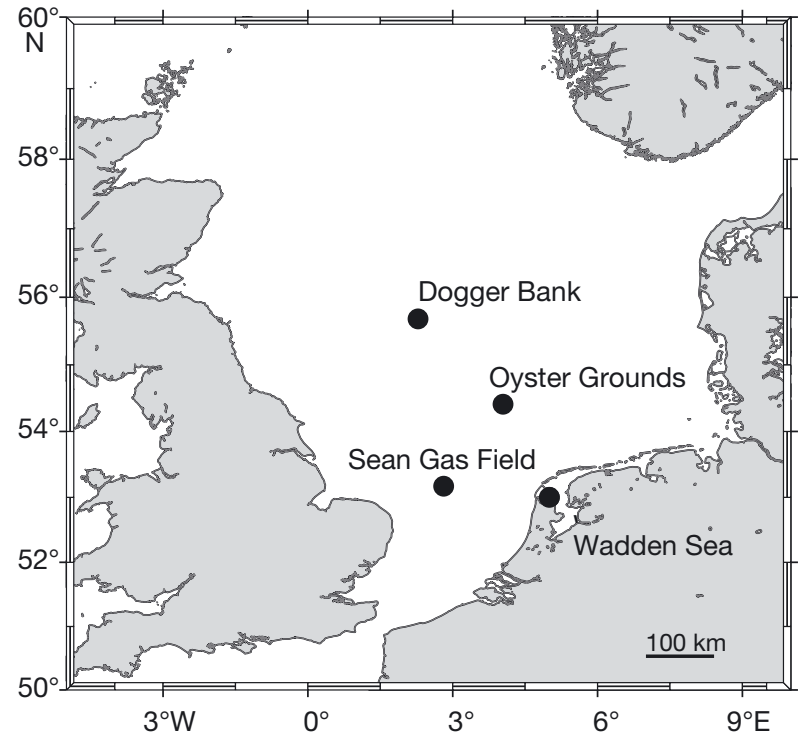

Fig. 2. Transplantation locations of blue mussels Mytilus edulis in the North Sea 

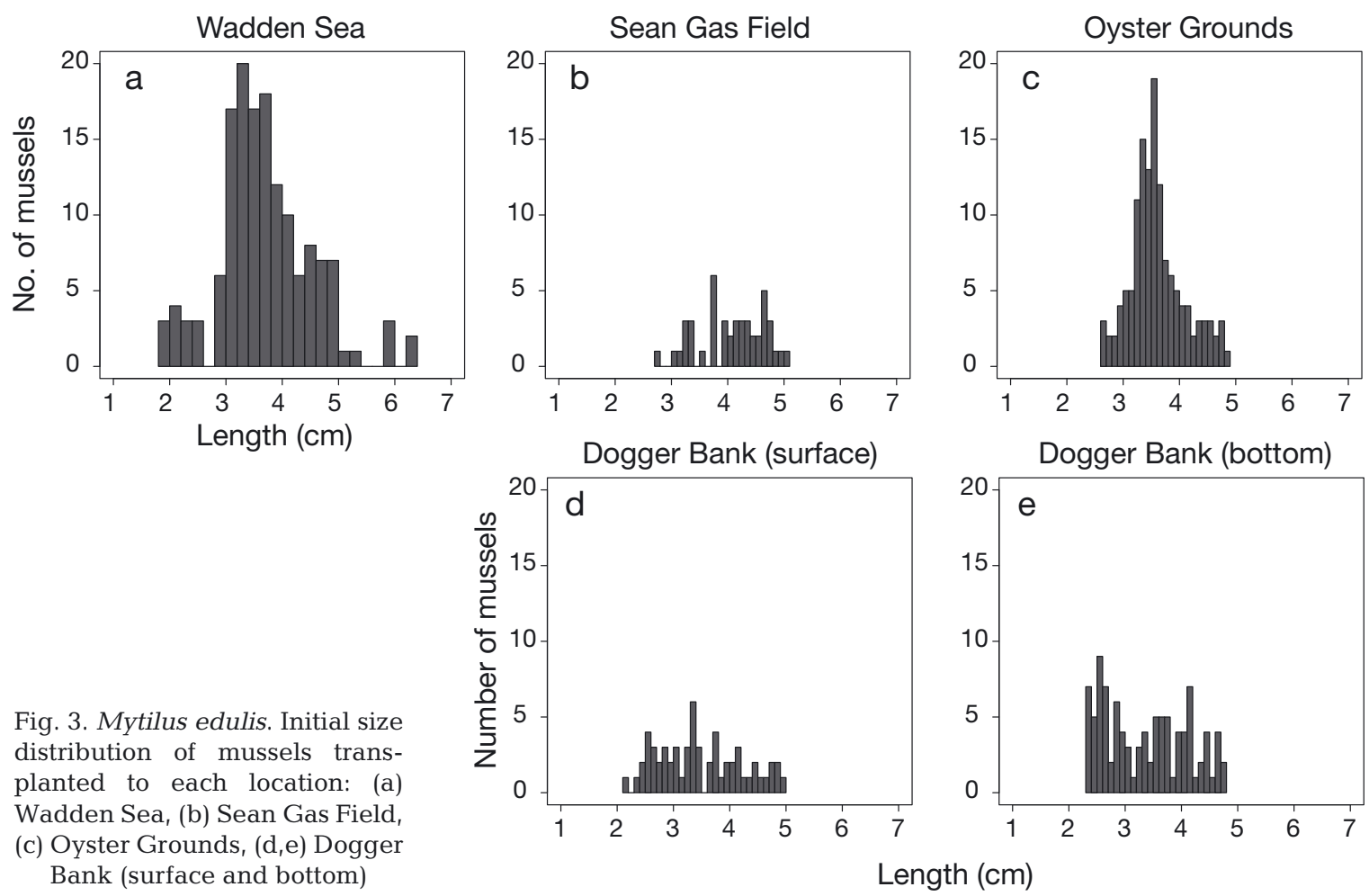

Fig. 3. Mytilus edulis. Initial size distribution of mussels transplanted to each location: (a) Wadden Sea, (b) Sean Gas Field, (c) Oyster Grounds, (d,e) Dogger Bank (surface and bottom)

Environmental conditions. Environmental condi-

2007 to September 2008. Between the start and end of this deployment period, 2 interim retrievals of the moorings took place (January 2008 and April 2008) during which the individually marked mussels were re-measured and small sets of individuals were taken out for weight determination. For the Dogger Bank location, nets with mussels were also positioned at the surface. Hence for this location, growth data from both surface and bottom were collected.

The mortality of the entire experimental population of mussels at all locations was low $(\sim 2 \%)$. At the Dogger Bank surface location, some fouling by macroalgae in the surface nets occurred during the spring-summer period. The nets transplanted to the Wadden Sea location experienced fouling by barnacles and adhering mud. This fouling was removed monthly at the times the mussels were re-measured. Thus the negative effects on mussel growth and performance are expected to be small. tions were quantified from field measurements of water temperature and chlorophyll a ( $\mathrm{chl}$ a) concentration at each location. For the Wadden Sea, the Royal Netherlands Institute for Sea Research maintains a research jetty, situated on the northern shore of the Marsdiep, a tidal inlet, which connects the Western Dutch Wadden Sea with the North Sea. At this location, continuous observations are being made on sea surface temperature and salinity (van Aken 2008a,b) and on chl a concentrations (Philippart et al. 2010). Since this monitoring station is located close to the transplantation location of the mussels (see next section), these measurements were used as input data for the model (Fig. 4). At this location, total particulate matter (TPM) was estimated, and inorganic material concentration was computed as the difference between TPM and algal weight. TPM estimation used an empirically based

Table 5. Experimental details at the 4 locations

\begin{tabular}{|lccccc|}
\hline Name & Location & Origin & Depth (m) & Experiment period & No. mussels used \\
\hline 1. Wadden Sea & $53.01^{\circ} \mathrm{N}, 4.80^{\circ} \mathrm{E}$ & Egmond & Surface & Dec 2006 to Aug 2009 & 148 \\
2. Sean Gasfield & $53.17^{\circ} \mathrm{N}, 2.81^{\circ} \mathrm{E}$ & Wash/Lowestoft & 31 & Jan 2008 to Aug 2008 & 45 \\
3. Oyster Grounds & $54.41^{\circ} \mathrm{N}, 4.04^{\circ} \mathrm{E}$ & Egmond/Wash/Lowestoft & 45 & Nov 2007 to Aug 2008 & 132 \\
4. Dogger Bank & $55.68^{\circ} \mathrm{N}, 2.28^{\circ} \mathrm{E}$ & Wash/Lowestoft & Surface & Nov 2007 to Aug 2008 & 59 \\
5. Dogger Bank & $55.68^{\circ} \mathrm{N}, 2.28^{\circ} \mathrm{E}$ & Wash/Lowestoft & 85 & Nov 2007 to Aug 2008 & 98 \\
\hline
\end{tabular}



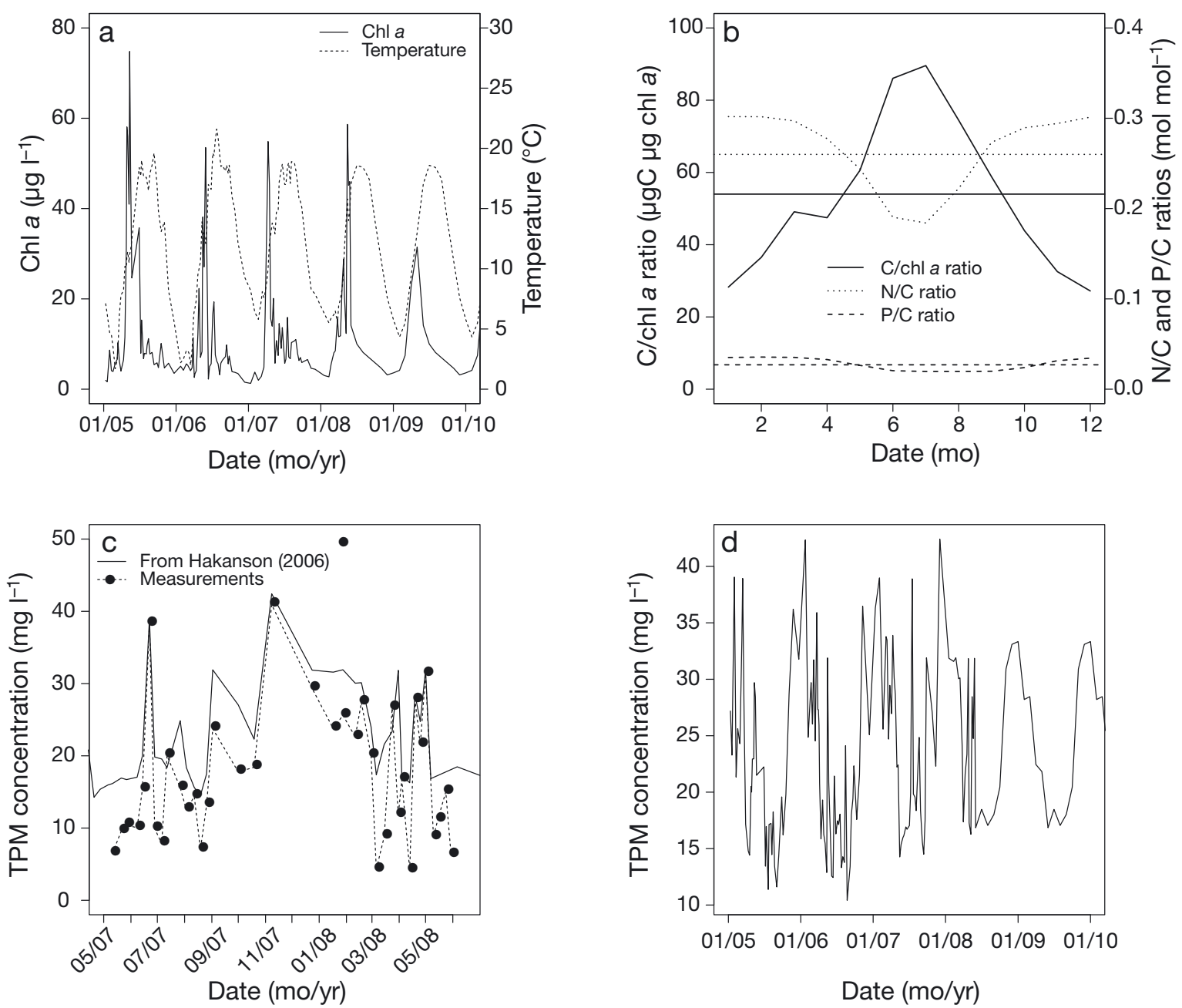

Fig. 4. Environmental conditions measured at the Wadden Sea location and used as model input data: (a) temperature and chlorophyll $a(\mathrm{chl} \mathrm{a}) ;(b)$ seasonal pattern of chl $a$, nitrogen and phosphorus to carbon ratios in food particles (the straight lines represent their annual average value). Model results provided by the GETM-ERSEM model (www.nioz.nl/northsea_model): (c) measured and estimated total particulate matter (TPM) concentrations for the period with available data and (d) TPM concentrations

model, proposed by Håkanson (2006), to quantify the relationship between TPM, salinity and Secchi depth. The formulation was tested for a period when all the measurements were available (Fig. 4c) and then used to estimate TPM concentrations for the periods in which no measurements were available.

The environmental conditions for the offshore North Sea locations were measured with semiautonomous moorings and lander systems, to which the mussels were attached. The mooring systems were equipped with self-logging fluorescence, turbidity and CTD sensors. Details of the moorings and landers are given by Suratman et al. (2010) and Painting (2010). Chl a to carbon and nitrogen/phosphorus to carbon ratios were used to convert chloro- phyll observations into food concentration in terms of carbon, nitrogen and phosphorus content, necessary as model input. Average results from the GETMERSEM model were used to obtain a seasonal pattern of those nutrient ratios at all 4 locations (Fig. 5). More detailed description on the GETM-ERSEM model and its implementation in the North Sea can be found at www.nioz.nl/northsea_model and in BarettaBekker et al. (1997). To assess the implications of the assumptions made on the forcing functions, namely on the determination of the inorganic material concentration and conversion from chl $a$ to carbon, nitrogen and phosphorus, some additional model scenarios were performed. The first scenario is a repetition of the reference scenario but assuming $50 \%$ lower inorganic material concentrations to assess the 

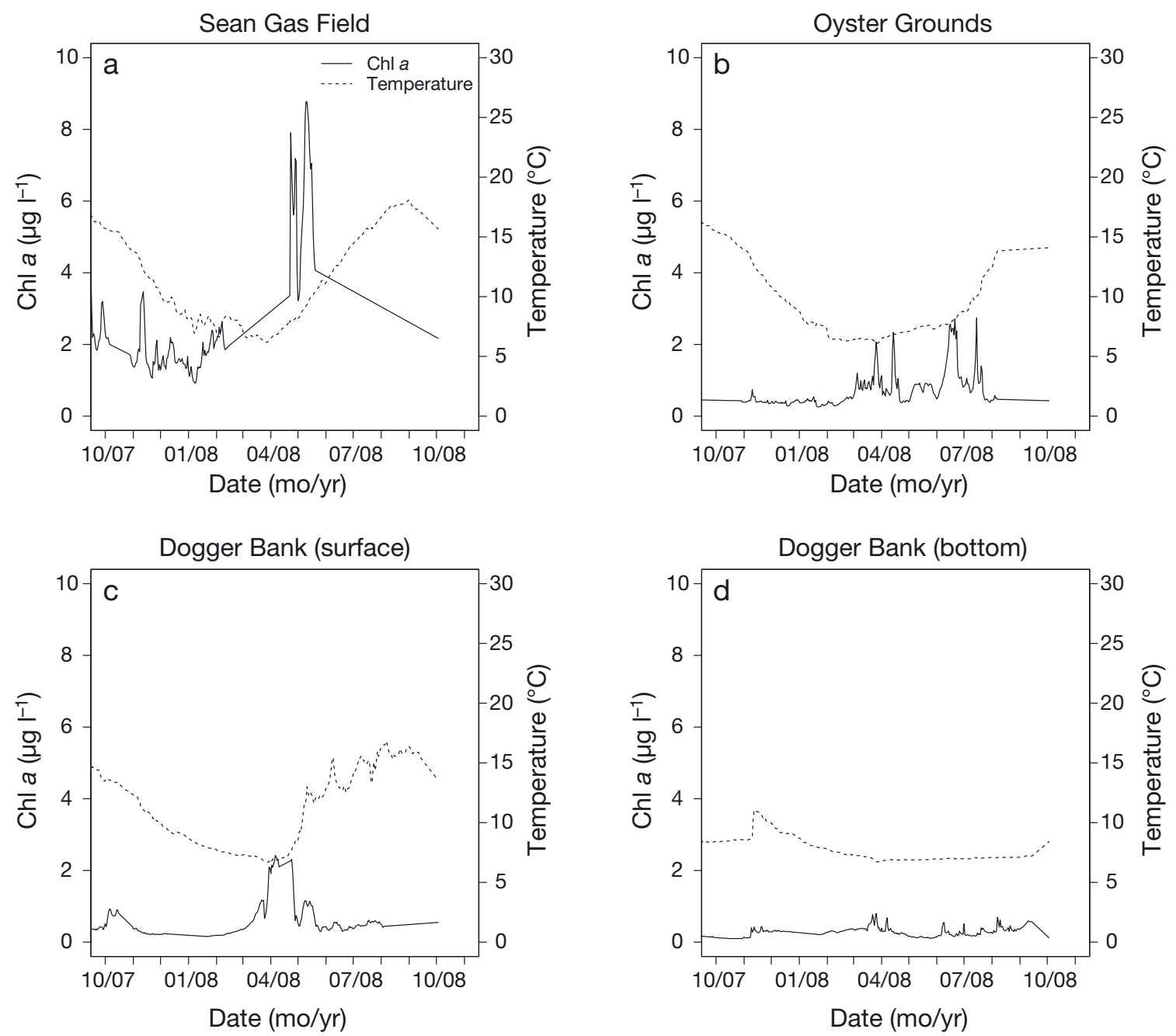

Fig. 5. Environmental conditions (temperature and chl a concentration) measured at (a) Sean Gas Field, (b) Oyster Grounds and $(\mathrm{c}, \mathrm{d})$ Dogger Bank (surface and bottom)

importance of food quality on mussel growth. Two other scenarios were performed: (1) assuming a constant average value for the carbon:chlorophyll ratio, to assess the importance of the seasonal variation in food quantity; and (2) assuming a constant average value for nitrogen:carbon and phosphorus:carbon, to quantify the importance of the seasonal variation in food composition.

Comparison between predictions and observations. The same model and the same parameter set were used to model length and weight growth of each mussel at each of the 4 locations.

The model simulations in the present study only differed with respect to the location-specific forcing function (food, temperature) and initial conditions (amounts of reserve, structure, reproduction buffer and level of maturity). The initial conditions for each mussel were estimated using the results of a pre-run of the model for a 'born and raised' mussel living in average environmental conditions. Initial structure was estimated by length measured at the beginning of the experiment and initial reserve content estimated by combining the seasonal pattern of reserve density resulting from the pre-run simulation with the day of year of the start of the experiment. For each location, the results were analysed on an individual basis, i.e. comparing observations and model predictions for each mussel separately, and then the overall results were analysed in terms of the average performance of the model predictions. The difference between model predictions and field observations was quantified in terms of a relative error computed as:

$$
E_{r}=\left|\frac{Y-\hat{Y}}{Y}\right|
$$

where $Y$ and $\hat{Y}$ are the observations and the model predictions, respectively. 


\section{RESULTS}

\section{Wadden Sea}

Fig. 6 presents model predictions of mussel characteristics for a 'born and raised' mussel under average daily environmental conditions, as measured in the Marsdiep (temperature, chl a and inorganic particle concentration) obtained at the Wadden Sea location. Total mussel dry weight was computed as the sum of structure, reserve and reproduction buffer content of the bivalve, as described in Table 3. In Fig. 6a, dry weight versus length predictions are compared with observations from the subset of mussels sacrificed at the beginning of the experiment. For the same predicted length, a range of predicted dry weight values was found, depending on the reproduction buffer content. This buffer is determined by the number and timing of spawning events also predicted by the model. The difference between model estimates and real observations was higher for mussels with higher length, but it was also in this range that the observations showed more scatter. After $16 \mathrm{yr}$ of simulation, the average 'born and raised' mussel is about $7 \mathrm{~cm}$ long, which is within the common range of lengths found in field observations, i.e. between 5 and $10 \mathrm{~cm}$ (MarLIN 2009).

All model results indicated a strong seasonal pattern with high growth in the spring/summer season and low growth during the autumn/winter season. This pattern is consistent with the seasonal cycle of temperature and food availability for a typical year (Fig. 4). Temperature starts to increase during the beginning of spring (April) followed by an increase in chlorophyll concentration. The increase in food availability and temperature promotes high growth for the mussel during a period of about 5 mo. The decline in chlorophyll during summer until the end of the year
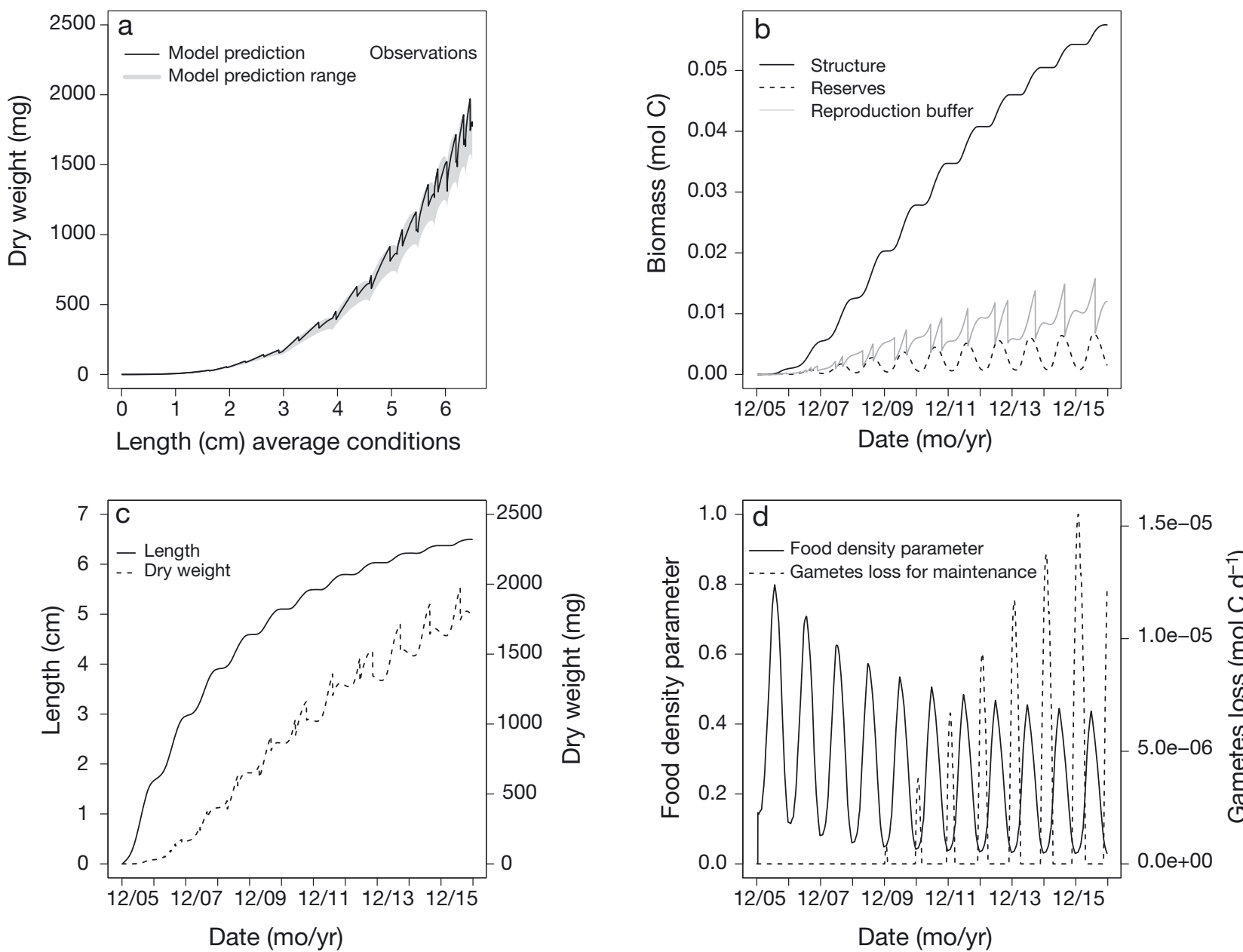

Fig. 6. Mytilus edulis. Model predictions for a 'born and raised' mussel living at average environmental conditions in the Wadden Sea: (a) mussel length vs. dry weight, (b) mussel biomass distribution by compartment, (c) mussel growth over time and (d) food density parameter (dimensionless) and gametes used for somatic maintenance needs 
and the temperature decrease in autumn result in lower mussel growth. In this period of low food availability, the mussel is using its reserve to maintain itself. Model results show that mussels of more than $4.5 \mathrm{~cm}$ may even use the reproduction buffer content to fuel the high somatic maintenance costs, shown in Fig. 6d. Spawning events, controlled by temperature and the fraction of gametes in the organisms ( $T^{\text {spawn }}$ and GSR ${ }^{\text {spawn }}$ thresholds), are responsible for the sharp decline of the reproduction buffer content. The model predicts an interval of about $1 \mathrm{yr}$ between spawning events (late spring/summer), but also indicates that in some years a second spawning event can occur if the first event is early in spring. Both predictions are consistent with field observations (Cardoso et al. 2007).

As described before, the 'mussel born and raised' scenario was used to establish the initial conditions (structure, reserve and reproduction buffer from measured initial length) of the mussels. Model simulations were then performed for each mussel $(n=148)$ considering the same forcing functions and individual parameters, changing only the initial conditions of each mussel. Fig. 7 represents some of the obtained results, including examples of shell length observations in comparison with the predicted length for 4 particular mussels (B209, B127, B144 and B219). This shows that the main seasonal pattern observed both in the data and in the model is that the mussel growing season starts with the increase in temperature and chl a concentration in the water column during spring. This contrasts with slow growth observed during autumn and winter. Although the model is able to predict this pattern, the particular predictions for mussels B127 and B209 show a higher growth during the growing season of the first year, compared with the observations (Fig. 7b). For mussels B144 and B219 (Fig. 7a), the model predictions are close to the observations even with very different initial lengths. The overall relative error (relative difference between observations and model) for these mussels is about $2 \%$, showing that the initial length does not determine the goodness of fit of the model prediction. It is also interesting to note that mussels B209 and B219, which had about the same size at the beginning of the experiment, showed a significant difference in their observed growth pattern. Fig. 7 also presents the overall result for model predictions versus observations for growth, both in terms of shell length and in terms of weight, for each data point (white dots) and their averages (black dots). The high variability in growth in the observations is clearly shown. The relative difference between the model and observations was about
$30 \%$, and there was a tendency for lower predicted values. In terms of weight increase, the average relative error was much higher (about $75 \%$ ).

Fig. 8a,b shows the comparison between observed lengths and model predictions in the simulated scenarios for 2 particular mussels, and Fig. 8c,d represents the average result of shell length and weight growth for the reference scenario (black dots) and for the scenario with half inorganic material concentration (white dots). The results show that a decrease in inorganic material concentration does have a significant effect on increasing mussel growth. The overall result suggests that this higher growth rate compared with the reference scenario slightly improves in the model predictions, reducing the tendency for lower model predictions. In fact, for about $90 \%$ of the mussels (see Fig. 8a for an example of these and Fig. 8b for an example of the remaining $10 \%$ ), the first scenario, with half inorganic material, results in better model predictions. The differences between the scenarios on food quantity and composition and the reference situation are not very significant; the highest difference is about $0.2 \mathrm{~cm}$ in a mussel with a $5 \mathrm{~cm}$ long shell, which represents a change of about $4 \%$ in length.

\section{All North Sea locations}

The same modelling methodology was followed for the other locations in the North Sea, and the results obtained for the reference scenarios are summarized in Fig. 9. The model goodness of fit can be assessed by the distance between the dots and the diagonal line, which represents the perfect fit. Length growth results for each location are summarized in terms of a straight line connecting the average values of growth observed for all mussels. Dogger Bank (bottom) is represented by a single dot because at this location, all mussels showed low growth and were all averaged (Fig. 9b). The Wadden Sea and Sean Gas Field are close to the diagonal, and for the Oyster Grounds, the results show the correct slope but with higher observed values. The low length growth found for the Dogger Bank bottom location is in agreement with the model predictions, and the strong contrast with the results obtained at the Dogger Bank surface location. In terms of weight, the results obtained for the Wadden Sea show the largest difference between estimates and observations (Fig. 9d). For the other locations, despite the high variability in the data, the comparison between model predictions and observations is relatively close to the perfect fit. 

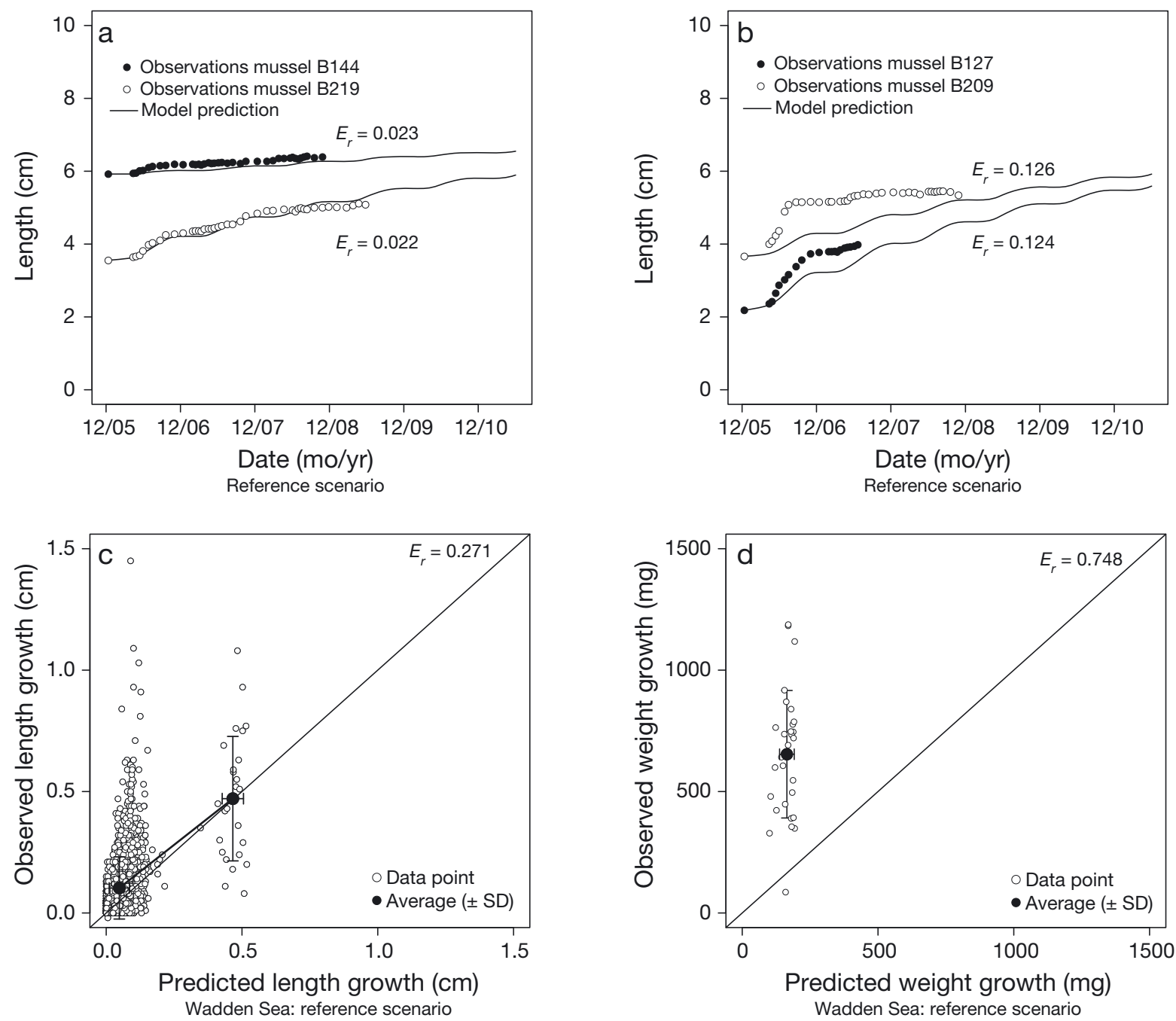

Fig. 7. Mytilus edulis. Model predictions vs. observations in the Wadden Sea: (a) shell length comparison for bivalves B144 and B219 as good examples of model predictions, (b) shell length comparison for bivalves B127 and B209 as poor examples of model predictions, (c) shell length growth, and (d) weight growth. See 'Results: Wadden Sea' for further details. The relative error is computed as $E_{r}=|(Y-\hat{Y}) / Y|$, where $Y$ and $\hat{Y}$ are the observations and the model predictions, respectively

\section{DISCUSSION}

The same model and parameter set were used to predict mussel growth in the transplantation experiments at all 4 locations. The underlying idea is that a generic mussel model should represent an average (growth) performance of mussels under given environmental conditions. The observations used in the study refer to particular mussels, and it is not always correct to average the data, particularly if mussels have different sizes. For that reason, the model was evaluated by a combination of 2 different methodologies: first by comparing observations and predictions for individual mussels and second by computing the average relative error per location. The individual mussel observations show a clear seasonal pattern. The growing season is driven by an increasing temperature and food availability during spring and summer. The model is well able to reproduce this for all locations, suggesting that the main and seasonal processes are well described. The analysis of the overall results of predictions on length and weight growth (Fig. 9) are also satisfactory, especially when considering that the model was not calibrated or fitted to these particular experimental observations. However, several assumptions and choices had to be made and with that some uncertainties are associated with the results.

Temperature and chl a measurements were used to characterize the environmental conditions at each of 


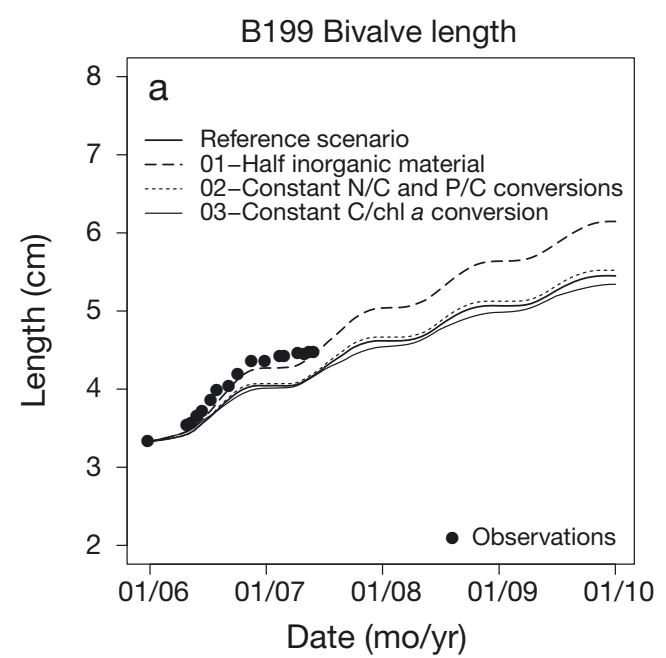

Mussel length growth: model vs. observation

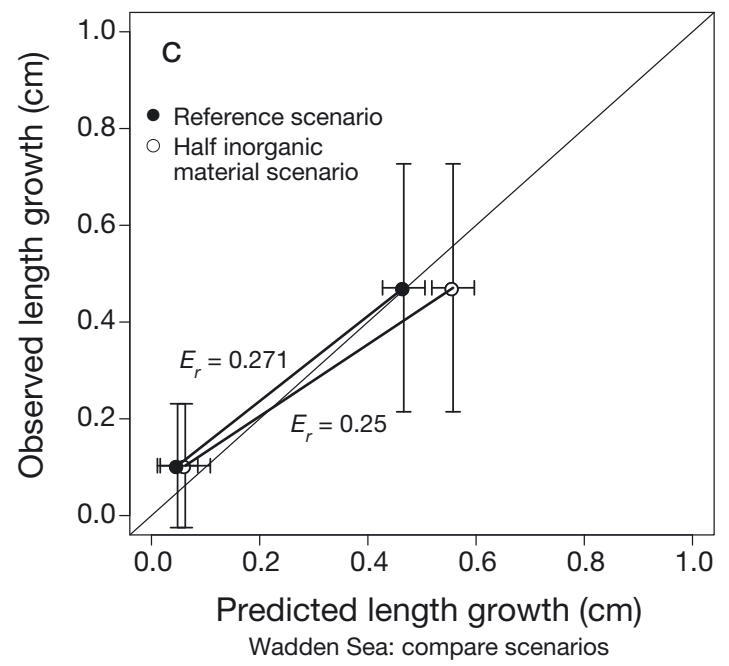

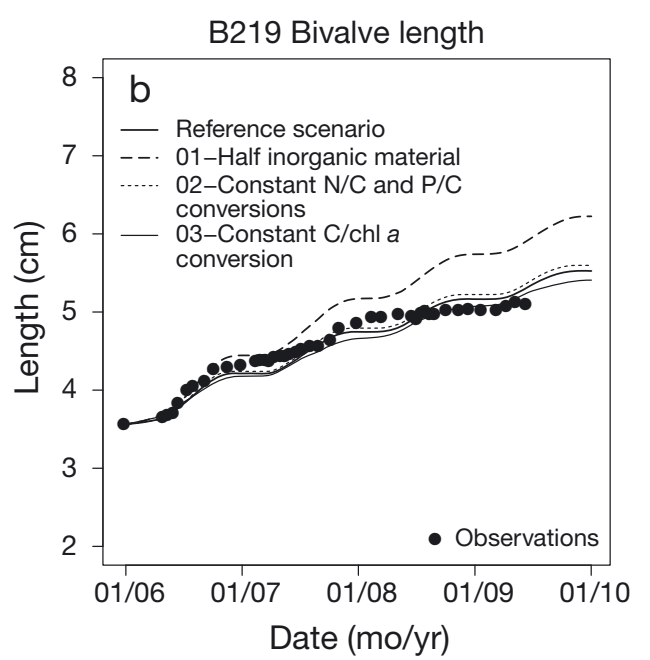

Mussel weight growth: model vs. observation

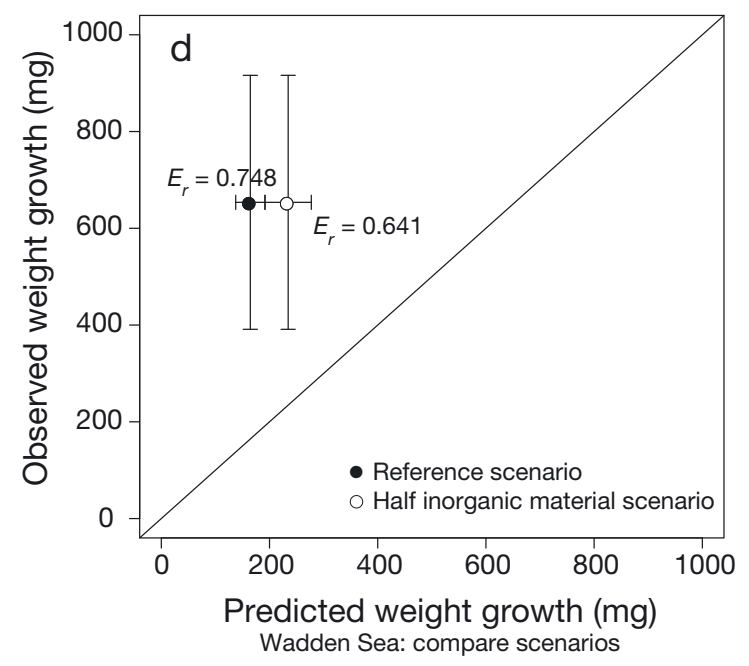

Fig. 8. Mytilus edulis. Model predictions vs. observations in the Wadden Sea: (a,b) bivalves B199 and B219 as examples of shell length predictions in 4 different scenarios of food quality, $(c, d)$ length and weight growth (means \pm SD), respectively, in the reference scenario and in the scenario with half inorganic material concentration. The relative error is computed as in Fig. 7

the locations. Although fundamental, this information is not fully representative of the conditions at the site. Chl a is used as a proxy for food concentration and composition, combined with chlorophyll to carbon and nitrogen/phosphorus conversion factors. To include the seasonal variation of these ratios in the North Sea, we had to use ERSEM model outcomes, as this type of information was not available from the measurements at these different locations. Additionally, the Wadden Sea simulations used estimates of inorganic material concentration in the water column obtained by an empirical relationship between this property and measurements of Secchi depth and salinity, proposed by Håkanson (2006). The use of these assumptions instead of measured data can also cause some deviations between model predictions and observations of mussel length or weight. The feeding processes module enables the evaluation of some of the assumptions made on the food characterization due to the incorporation of food quality and composition in the assimilation rate computation. Differences in mussel growth between the different modelling scenarios performed are shown in Fig. $8 \mathrm{a}, \mathrm{b}$, for 2 individual mussels. The scenario analysis confirms the negative effect of high suspended inorganic particles on mussel filtration and consequently on the growth of the organism, which is in agreement with several other studies (see review Riisgård 2001, and references therein). This is an important result and strengthens the model potential 

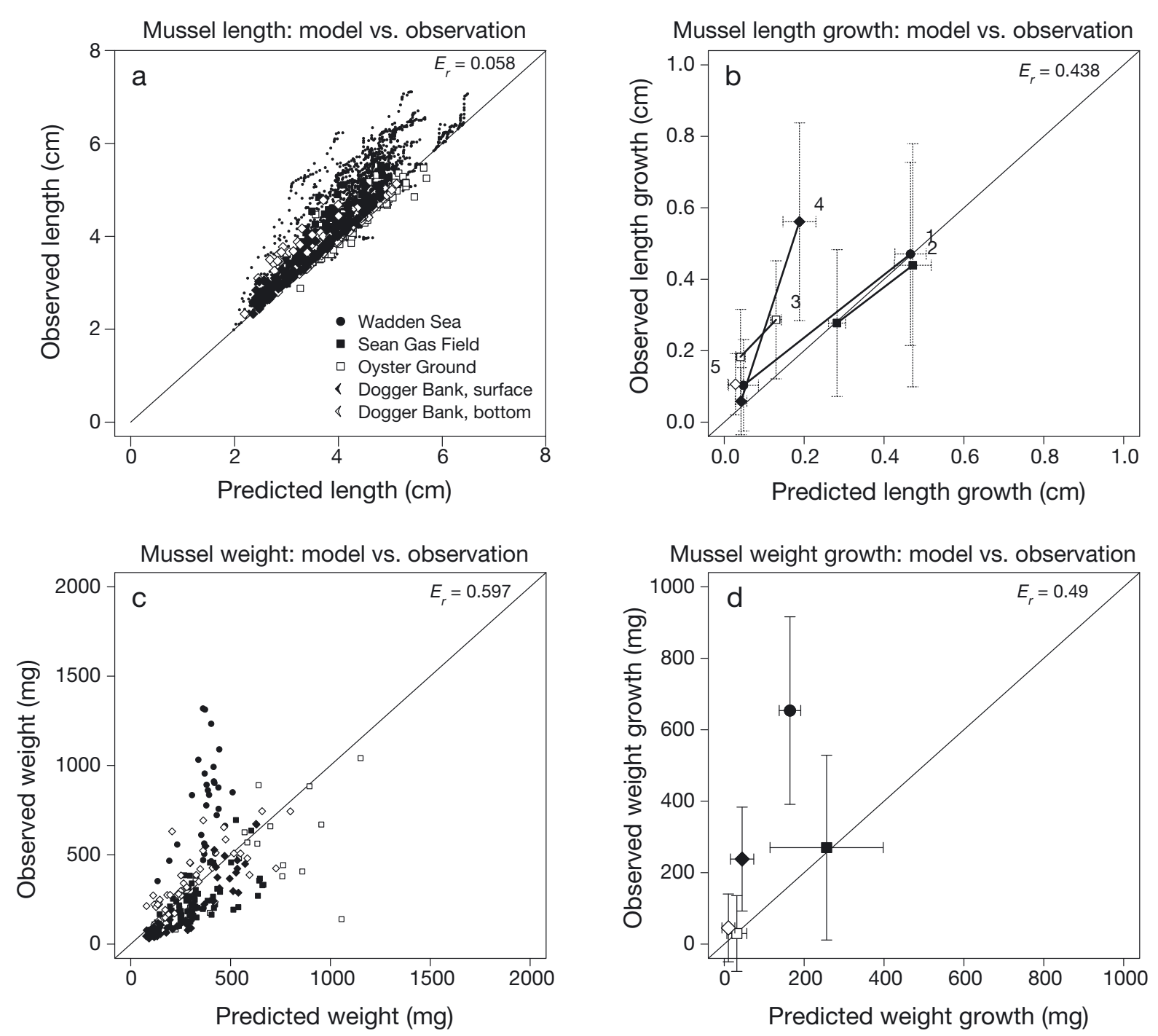

Fig. 9. Mytilus edulis. Model predictions vs. observations at the 4 locations: (a) shell length, (b) shell length growth (mean $\pm \mathrm{SD}$ ), (c) weight, and (d) weight growth (mean $\pm \mathrm{SD}$ ). The relative error is computed as in Fig. 7

for mussel growth simulation in estuarine and coastal environments.

The model predictions improved in the scenario of half inorganic material concentration. This could be explained by the fact that the experiment was conducted inside the harbour and the measurements were taken at the jetty station, located outside the harbour, more exposed to coastal transport of TPM and wind-induced waves. The comparison of scenarios also suggests that the influence of inorganic particles is much more important than the influence of seasonal changes in food composition. These results are also important for the design of future experiments meaning that with limited resources, the main effort in measurements should be on the TPM deter- minations rather than on frequent seasonal food composition estimations. Therefore, to obtain better model predictions, data should be available for TPM concentrations, temperature and food concentration (phytoplankton concentration and/or chlorophyll concentrations combined with $\mathrm{C}: \mathrm{chl} a$ ratios). The measurements should be made frequently (on the order of weeks or at least monthly), and food composition (mainly $\mathrm{C}, \mathrm{N}$ and $\mathrm{P}$ ) should be measured at the experiment location, preferably on a seasonal time scale. Frequent mussel length monitoring and periodic mussel sacrifices for weight determination are essential for a more detailed comparison with the model predictions. Monitoring of gonadal development and spawning events could also be of great 
help to evaluate the reproduction buffer handling rules assumed in the model.

Knowledge on the start conditions of each mussel (length and reserve density) is also critical for model implementation, particularly if the simulation period is short and if the results are compared in terms of growth (different between the end point value and the start). In this study, start conditions of mussels were based on a previous model simulation for a 'born and raised' mussel living in average seasonal environmental conditions, resulting in a clear seasonal pattern of the organism reserve density. This seasonal pattern, combined with the starting date of the experiment, was used to estimate the initial reserve density of each mussel.

The agreement between predictions and observations was higher, and also more reliable, for length measurements than for weight. In fact, the uncertainties associated with weight can be very significant. The organism weight depends very much on the spawning events and on the usage of energy reserves during long periods of food shortage (Bayne et al. 1978, 1982). There was large variability in observed length and weight growth of the mussels within each site. This variability is attributed to different individual performance, different initial conditions and to some extent to differences in experiencing ambient conditions despite the careful planning of the experiment. Individual performance will also depend on the organism's condition, i.e. reserve density and health. Even when mussels had similar lengths, they may have differed in condition since they were collected in a natural population living in a spatially and temporally variable environment. The model is not able to reproduce specific adaptations of the individual to specific environmental conditions, e.g. temperature ranges or sediment concentrations in the water column. The parameters used in the model were estimated by Saraiva et al. (2011a) using literature data describing results collected from different locations, experiments and authors and as such attempt to represent a parameter set for an 'average mussel' rather than a specific individual from a specific location. Therefore, it is believed that, if needed, the model performance for each location could be improved by using detailed data and/or site-specific assumptions. Although there was significant variability in the observed growth of the mussels, they all followed the same seasonal pattern, which was well predicted by the model at all locations.

\section{CONCLUSIONS}

This study aimed to evaluate the performance of a generic model for individuals to predict mussel length and weight growth given the environmental conditions. The model results were compared with observations made at the individual level without adapting parameters. Despite the high variability found in field observations, the model was able to reproduce the seasonal pattern of the observations on length and weight growth. Length was better predicted than weight, probably due to the high influence of spawning events and food limitation periods on the total mussel weight ( \pm 10 to $15 \%$ ), as well as the high uncertainty in the initial weight conditions. One important conclusion of this study is that the influence of inorganic material concentration on mussel growth is significant, and the model suggests that it could even be more important than seasonal changes in food composition. Model predictions can be improved if measurements of inorganic material concentration are available. The model was tested at 4 different locations with different environmental conditions. From the results, we conclude that the 'average mussel' model can reasonably reproduce the average of the mussels at each location. This supports the model's ability to correctly describe the main processes involved in mussel growth and confirms its potential use in upscaling these processes to the level of population dynamics.

Acknowledgements. This work was supported by Fundação para a Ciência e a Tecnologia, Portugal (SFRH/BD/44448/ 2008). The North Sea mussel growth data were collected within the Dutch National Research Programme Climate Changes Spatial Planning (BSIK project 'Klimaat voor Ruimte'-A6) and mooring and lander systems which were deployed and maintained by CEFAS (Lowestoft) Marine Ecosystem Connections project funded by Defra (Department for food and rural affairs) with contract number ME3205. We also thank P. Ruardij for providing GETMERSEM results and discussions.

\section{LITERATURE CITED}

Bacher C, Gangnery A (2006) Use of dynamic energy budget and individual based models to simulate the dynamics of cultivated oyster populations. J Sea Res 56: 140-155

Bacher C, Heral M, Deslous-paoli J, Razet D (1991) Modèle énergétique uniboite de la croissance des huîtres (Crassostrea gigas) dans le bassin de Marennes-Oléron. Can J Fish Aquat Sci 48:391-404

Baretta-Bekker J, Baretta J, Ebenhöh W (1997) Microbial dynamics in the marine ecosystem model ERSEM II with decoupled carbon assimilation and nutrient uptake. J Sea Res 38:195-211 
Bayne B, Holland D, Moore M, Lowe D, Widdows J (1978) Further studies on the effects of stress in the adult on the eggs of Mytilus edulis. J Mar Biol Assoc UK 58:825-841

Bayne B, Bubel A, Gabbott P, Livingstone D, Moore M, Lowe D (1982) Glycogen utilization and gametogenesis in Mytilus edulis. Mar Biol Lett 1:89-105

> Bayne BL, Hawkins AJS, Navarro E, Iglesias IP (1989) Effects of seston concentration on feeding, digestion and growth in the mussel Mytilus edulis. Mar Ecol Prog Ser 55:47-54

Brey T (2001) Population dynamics in benthic invertebrates. A virtual handbook. Version 01.2. Available at www. thomas-brey.de/science/virtualhandbook

Cardoso J, Dekker R, Witte J, van der Veer H (2007) Is reproductive failure responsible for reduced recruitment of intertidal Mytilus edulis L. in the western Dutch Wadden Sea? Mar Biodivers 37:83-92

Foster-Smith R (1975) The effect of concentration of suspension on the filtration rates and pseudofaecal production for Mytilus edulis L., Cerastoderma edule (L.) and Venerupis pullastra (Montagu). J Exp Mar Biol Ecol 17:1-22

Grant J, Bacher C (1998) Comparative models of mussel bioenergetics and their validation at field culture sites. J Exp Mar Biol Ecol 219:21-44

Håkanson L (2006) The relationship between salinity, suspended particulate matter and water clarity in aquatic systems. Ecol Res 21:75-90

Hummel H, Fortuin A, Bogaards R, de Wolf L, Meyboom A (1989) Changes in Mytilus edulis in relation to short-term disturbances of the tide. In: Klekowski R, Falkowski L, Stycynska-Jurewicz E (eds) Proc 21st Eur Mar Biol Symp Ossolineum, Warsaw, p 77-89

Kiørboe T, Møhlenberg F, Nøhr O (1980) Feeding, particle selection and carbon absorption in Mytilus edulis in different mixtures of algae and resuspended bottom material. Ophelia 19:193-205

Kooijman S (1986) Energy budgets can explain body size relations. J Theor Biol 121:269-282

Kooijman S (1998) The synthesizing unit as a model for the stoichiometric fusion and branching of metabolic fluxes. Biol Chem 73:179-188

- Kooijman S (2006) Pseudo-faeces production in bivalves. J Sea Res 56:103-106

Kooijman S (2010) Dynamic energy and mass budgets in biological systems, 3rd edn. Cambridge University Press, Cambridge

Lika K, Kearney M, Freitas V, van der Veer H and others (2011) The 'covariation method' for estimating the parameters of the standard dynamic energy budget model. I. Philosophy and approach. J Sea Res 66:270-277

MarLIN (Marine Life Information Network) (2009) Marine Life Information Network. Marine Biological Association of the United Kingdom, Plymouth. Available at www. marlin.ac.uk

> Newell CR, Wildish D, MacDonald B (2001) The effects of velocity and seston concentration on the exhalant siphon area, valve gape and filtration rate of the mussel, Mytilus edulis. J Exp Mar Biol Ecol 262:91-111

Painting S (2010) Results of field work to quantify key processes affecting the flow of $\mathrm{C}, \mathrm{N}, \mathrm{O}$ and $\mathrm{Si}$ at study sites. Contract Milestone Report ME3205 10/03. CEFAS, Lowestoft

Philippart CJM, Iperen JMV, Cade GC, Zuur AF (2010) Long-term field observations on phytoplankton seasonality in a shallow coastal marine ecosystem, the Wadden Sea. Estuar Coasts 33:286-294

> Pouvreau S, Bourles Y, Lefebvre S, Gangnery A, Alunno-

Editorial responsibility: Inna Sokolova,

Charlotte, North Carolina, USA
Bruscia M (2006) Application of a dynamic energy budget model to the pacific oyster, Crassostrea gigas, reared under various environmental conditions. J Sea Res 56:156-167

Ren J, Ross A (2001) A dynamic energy budget model of the pacific oyster Crassostrea gigas. Ecol Model 142:105-120

Riisgård HU (2001) Physiological regulation versus autonomous filtration in filter-feeding bivalves: starting points for progress. Ophelia 54:193-209

Riisgård H, Møhlenberg F (1979) An improved automatic recording apparatus for determining the filtration rate of Mytilus edulis as a function of size and algal concentration. Mar Biol 52:61-67

Riisgård H, Randlov A (1981) Energy budgets, growth and filtration rates in Mytilus edulis at different algal concentrations. Mar Biol 61:227-234

Rosland R, Strand O, Alunno-Bruscia M, Bacher C, Strohmeier $T$ (2009) Applying dynamic energy budget (DEB) theory to simulate growth and bio-energetics of blue mussels under low seston conditions. J Sea Res 62:49-61

Ross A, Nisbet R (1990) Dynamic model of growth and reproduction of the mussel Mytilus edulis L. Funct Ecol 4: 777-787

Saraiva S, van der Meer J, Kooijman S, Sousa T (2011a) DEB parameters estimation for Mytilus edulis. J Sea Res 66: 289-296

Saraiva S, van der Meer J, Kooijman S, Sousa T (2011b) Modelling feeding processes in bivalves: a mechanistic approach. Ecol Model 222:514-523

Scholten H, Smaal A (1998) Responses of Mytilus edulis L. to varying food concentrations: testing EMMY, an ecophysiological model. J Exp Mar Biol Ecol 219:217-231

Slobodkin L, Richman S (1961) Calories/gm. in species of animals. Nature 191:299

Smaal AC, Vonck APMA (1997) Seasonal variation in C, N and $\mathrm{P}$ budgets and tissue composition of the mussel Mytilus edulis. Mar Ecol Prog Ser 153:167-179

Suratman S, Weston K, Greenwood N, Sivyer D, Pearce D, Jickells T (2010) High frequency measurements of dissolved inorganic and organic nutrients using instrumented moorings in the southern and central North Sea. Estuar Coast Shelf Sci 87:631-639

Troost TA, Wijsman JW, Saraiva S, Freitas V (2010) Modelling shellfish growth with dynamic energy budget models: an application for cockles and mussels in the Oosterschelde (southwest Netherlands). Philos Trans R Soc Lond B Biol Sci 365:3567-3577

van Aken HM (2008a) Variability of the salinity in the western Wadden Sea on tidal to centennial time scales. J Sea Res 59:121-132

van Aken HM (2008b) Variability of the water temperature in the western Wadden Sea on tidal to centennial time scales. J Sea Res 60:227-234

van der Veer H, Cardoso JF, van der Meer J (2006) The estimation of DEB parameters for various Northeast Atlantic bivalve species. J Sea Res 56:107-124

van Haren R, Kooijman SALM (1993) Application of a dynamic energy budget model to Mytilus edulis (L.). Neth J Sea Res 31:119-133

Widdows J, Fieth P, Worral C (1979) Relationship between seston, available food and feeding activity in the common mussel Mytilus edulis. PSZNI: Mar Ecol 50:195-207

- Winter J (1978) A review on the knowledge of suspensionfeeding in lamellibranchiate bivalves, with special reference to artificial aquaculture systems. Aquaculture 13: $1-33$

Submitted: August 8, 2011; Accepted: May 27, 2012

Proofs received from author(s): August 8, 2012 